Fecha de recepción: diciembre 2017

Fecha de aceptación: marzo 2018

Versión final: julio 2019
El diseñador como agente de cambio social: Análisis del caso Qom Lashepi Alpi

Susan Valverde Villamizar *

Resumen: El siguiente ensayo analiza el proyecto de diseño colaborativo Qom Lashepi Alpi, llevado a cabo por el colectivo Cooperativa de Diseño y el grupo organizado de mujeres artesanas de Juan José Castelli de la provincia del Chaco, Argentina. Se enfoca en el rol del diseñador como agente de innovación social para la creación de estilos de vida más sostenibles y se basa en el mapeo de la red de problemas sociales, económicos y ambientales que aquejan a esta comunidad de mujeres de la comunidad qom, con el objetivo de identificar posibles estrategias de apalancamiento y redes de colaboración. El caso se aborda desde el marco conceptual del Diseño para la Transición, el concepto de las comunidades resilientes propuesto por Manzini, específicamente el de localización cosmopolita, y finalmente se realiza una propuesta de palancas en puntos de intervención basados en las estrategias de apalancamiento propuestas por Donella Meadows.

Palabras clave: Diseño para la Transición - diseño colaborativo - innovación social - Chaco, Argentina - problemas perversos - localización cosmopolita - puntos de apalancamiento - comunidad qom, patrimonio.

[Resúmenes en inglés y portugués en la página 128]

(*) Susan Valverde Villamizar es diseñadora gráfica y publicitaria graduada de la Escuela Superior Politécnica del Litoral (Ecuador) y Licenciada en Negocios de Diseño y Comunicación, Universidad de Palermo (Argentina). Desde 2010 se desempeña en el rubro de la publicidad colaborando como Diseñadora y Redactora con y para empresas nacionales e internacionales de Ecuador y Argentina. Ha sido reconocida por distintos Festivales Publicitarios como el Cóndor, Festival Caribe, Marketing Hall of Fame y el Ojo de Iberoamérica.

\title{
El diseñador como agente de cambio social: Análisis del caso Qom Lashepi Alpi
}

En una sociedad atravesada y definida por el consumo exagerado, el diseñador carga con la responsabilidad de haber contribuido a la construcción de un falso ideal de bienestar. El 
problema del consumismo se encuentra ligado a otros iguales de complejos como el de la globalización, la contaminación del ambiente, las crisis económicas y la creciente brecha entre ricos y pobres, que desafían a los diseñadores a cuestionar su rol de manera urgente. En este escenario, donde la necesidad de transiciones sociales hacia futuros sostenibles resulta imperativa, surge la figura del Diseñador para la Transición (Irwin, 2012), quien hace frente a un nuevo paradigma del diseño, donde el trabajo colaborativo y transdisciplinario son fundamentales para encarar desafíos de alta complejidad.

El proyecto Qom Lashepi Alpi, desarrollado en conjunto por la Federación JUM, Cooperativa de Diseño y las mujeres artesanas qom de Castelli, fue elegido para el siguiente análisis ya que, a criterio de la autora, promueve la transición hacia un ejercicio más sostenible de la profesión; es un referente local del compromiso social y del cuestionamiento y reconstrucción del rol del diseñador; y demuestra el potencial del trabajo colaborativo entre diseñadores y comunidad para abordar problemas intrincados, como los que enfrentan las artesanas de Castelli.

El presente escrito consta de cuatro etapas, en la primera se describe el caso Qom Lashepi Alpi, en la segunda se revisa el rol del diseñador como agente de cambio, en la tercera se realiza el mapeo de la red de problemas que rodea al proyecto, y en la cuarta etapa se definen cursos de acción a través de tres herramientas del Diseño para la Transición: se escala el proyecto a través de los pathways for social innovation, se visualiza al proyecto como una localización cosmopolita y finalmente se realiza una propuesta de palancas en puntos de intervención basadas en las estrategias de apalancamiento de Donella Meadows.

\section{El proyecto Qom Lashepi Alpi}

El proyecto Qom Lashepi Alpi, en adelante QLA, es una iniciativa transdiciplinar que empezó a gestarse en 2013 por encargo de la fundación JUM ${ }^{1}$ (Junta Unida de Misiones) a Cooperativa de Diseño ${ }^{2}$, y que se desarrolla en conjunto con las mujeres artesanas qom, pertenecientes a la comisión L'taaraipi, de Juan José Castelli en el Chaco. Los objetivos del proyecto son: (1) ejecutar estrategias de producción-comercialización de manera autónoma y sostenible, (2) crear una marca que identifique al grupo de mujeres qom y sus productos, (3) destacar los conocimientos y trabajos ancestrales de la cultura indígena, (4) introducir estrategias de promoción y difusión del emprendimiento a nivel provincial y nacional, (5) fortalecer las habilidades de las jóvenes indígenas qom para el manejo de herramientas de comunicación (Fondo Ecuménico de Pequeños proyectos del Gran Chaco, 2015).

En este contexto, Cooperativa de Diseño es convocado para asistir técnicamente a las artesanas con el objetivo de incorporar estrategias de diseño en el proceso productivo de cestería y así contribuir a "revalorizar técnicas ancestrales y reivindicar la producción desde los sectores más oprimidos del pueblo" (Cooperativa de diseño, s.f.), además de visibilizar e insertar sus productos en nuevos canales comerciales.

Para encarar los objetivos mencionados anteriormente, el colectivo de diseño abordó el proyecto desde una mirada interdisciplinaria y desarrolló una metodología colaborativa. En consecuencia, las integrantes de Cooperativa de Diseño visitaron Juan José de Castelli cada dos meses, durante una semana. En estas visitas conocieron la plantación de palma 
caranday -también conocida como carandilla- de la comisión L'taaraipi, donde cultivan, cosechan, cortan, secan y tiñen la fibra con savias de diferentes especies de árboles y flores locales; conocieron el proceso productivo detrás de los productos, por ejemplo, descubrieron que tejer cada canasto toma aproximadamente 14 horas, trabajo que estas mujeres intercalan con tareas domésticas y de crianza (Daily Web, 2016). Este esquema de visita, le permitió a las diseñadoras conocer de primera mano los procesos productivos para generar propuestas viables, les dio a las artesanas espacio para internalizar estos nuevos conocimientos y para la ejecución de los productos que luego serían evaluados.

El proceso de colaboración implicó desafíos, entre ellos aceptar, entender y conciliar diferencias culturales e incluso de cosmovisión entre diseñadoras y artesanas, por ejemplo, las diseñadoras tuvieron que entender que no se puede "ir a imponer una metodología, sino generarla en conjunto" (Señal U Académico, 2017), esto las llevó a modificar su cronograma original por factores culturales propios de las qom, relacionadas con una noción más lenta de los tiempos, la sociabilización del trabajo y la conversación en su propio idioma, incluso tuvieron que dejar para el final la tarea de nombrar el proyecto ya que "desde nuestra cultura (...) cuando nos embarazábamos ya poníamos el nombre al bebé antes de tenerlo, y para ellas es al revés. El nombre surge después" (Cambariere, 2014). Otro de los desafíos fue involucrarse en la manufactura de los productos desde el inicio, para entender todo el proceso productivo de la cestería qom. Tuvieron que familiarizarse con el material, es decir, aprender sobre la cosecha, secado y preservación de la palma. Y a su vez entender la relación simbiótica que las mujeres qom mantienen con la naturaleza, ya que al recolectar la palma sólo arrancan 3 hojas únicamente, respetando los procesos de la planta sin perjudicar su crecimiento.

Durante las visitas, las diseñadoras del colectivo, analizaron el proceso productivo de los canastos para poder establecer y estandarizar la cantidad de material necesario y calcular costos (Cambariere, 2014). Además se eligió el punto de tejido que lleva menos tiempo de ejecución y la menor cantidad de hojas de palma con el fin de estandarizar la producción (Diaz, 2015). Este proyecto resultó en el desarrollo de una serie de productos entre ellos: canastos, canastos para bicicleta, paneras, prendedores, entre otros, además de la respectiva identidad de marca (Ver Figura 1).

En el proceso de confección de los productos también se realizaron modificaciones, por ejemplo, la incorporación de cintas de algodón de colores en lugar de manijas en los cestos, dichas cintas también sirven de soporte al cesto ya que al pasar por debajo del cesto le añadan estructura. Para las diseñadoras está intervención fue considerada como un logro ya que "-las artesanas- no solo estaban felices porque se ahorraban las manijas, que dan mucho trabajo, sino porque además con el tiempo y el peso éstas se rompían" (Cambariere, 2014). Por lo tanto, la inclusión de las cintas supuso una mejora en los tiempos de producción y una optimización en el ciclo de vida del producto.

Sin embargo los límites entre artesanía y diseño son muy delgados y traspasarlos puede generar controversia, por ejemplo, para Díaz (2015) la inclusión de manijas de algodón supone una mejora a nivel productivo, pero teme por el cuidado patrimonial de la técnica artesanal. Para la autora de este escrito la modificación de estos canastos no afecta la transmisión de saberes ancestrales y no supone una amenaza para la preservación del patrimonio cultural inmaterial, más bien se trata de un aporte del diseño, y de un ejercicio 


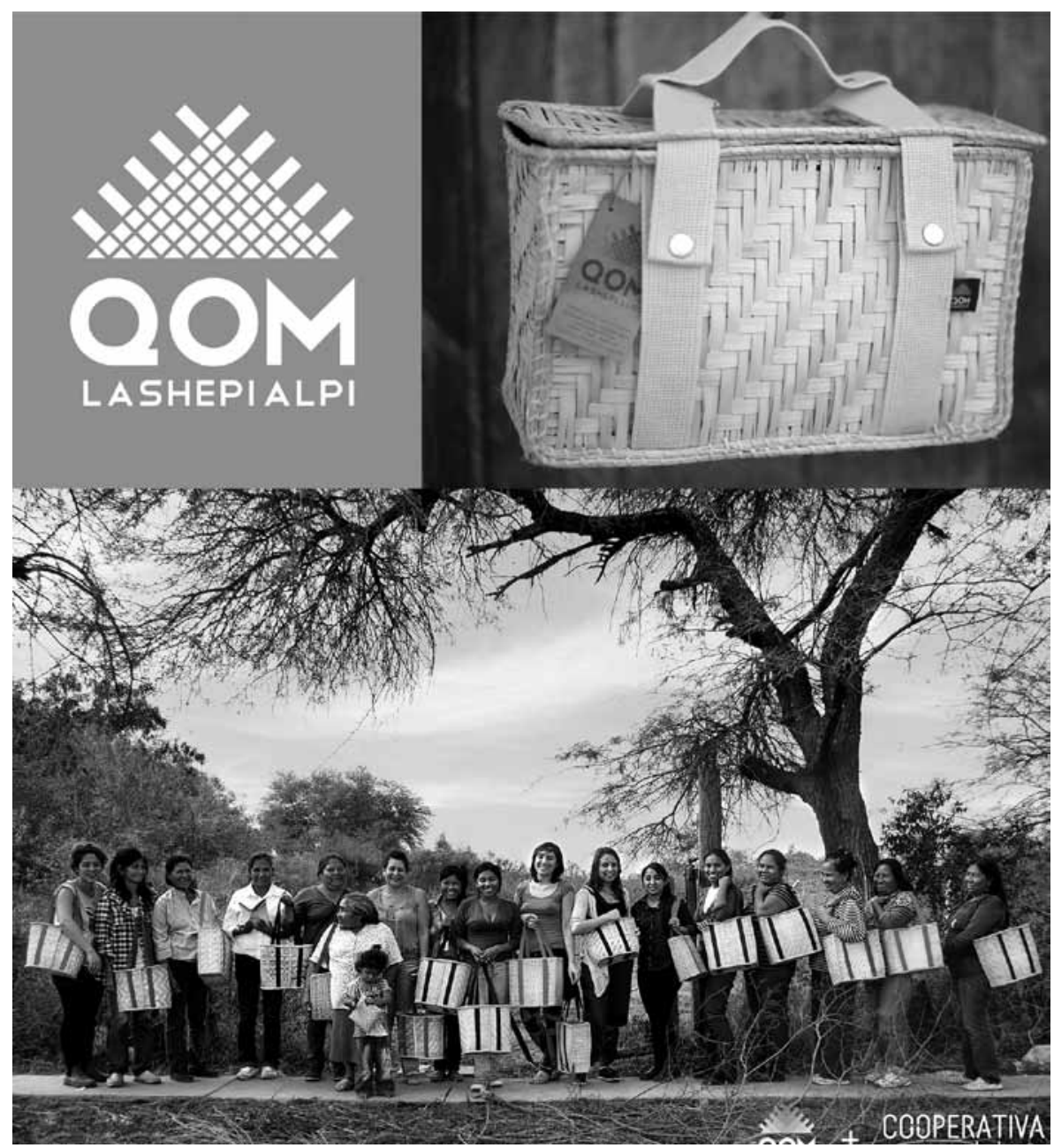

Figura 1. Cestería de mujeres artesanas Qom Lashepi Alpi, Castelli, el Chaco (Fuente web). 
de aprendizaje para las artesanas, una intervención que mejora el producto final, necesaria para lograr una mayor inserción de la producción en el mercado. Incluso se podría afirmar que esta optimización del producto lo vuelve más ético, ya que la estructura reforzada del canasto evita que éste se rompa con facilidad debido al peso, volviéndolo un producto más funcional y sostenible, más sensible a nuestras necesidades, por lo tanto esta intervención, en palabras de Tonkinwise (2004) no sólo nos libera de molestias existentes, sino también anticipa molestias futuras, de cierta forma el producto nos está cuidando.

Finalmente se desarrolló el proceso de identificación de la marca, para ello se definió un isologotipo y se realizaron piezas gráficas como etiquetas con el fin de diferenciar los productos y avisos para promocionarlos. La campaña publicitaria tiene por protagonistas a las artesanas qom, y en los avisos se las muestra usando los productos de su elaboración. Esta elección permite consolidar su identidad con orgullo y a su vez constituye un aporte valioso y necesario para equilibrar la representación de la mujer en los medios, al ofrecer referentes diversos tanto física como culturalmente. Al tratarse de una iniciativa pequeña, toda su comunicación se realiza en medios digitales, siendo Facebook el medio principal, donde se comunican las actividades, se mantiene contacto con proveedores y clientes, y se recepcionan los pedidos.

\section{El diseñador como agente de cambio}

La necesidad de transiciones sociales hacia futuros más sostenibles es la premisa central del Diseño para la Transición. Esta área emergente del diseño se preocupa por entender la interconexión de los sistemas sociales, políticos, económicos y naturales para proponer modificaciones en su estructura y redirigir el cambio hacia panoramas más positivos. Sobre esto, Di Bella basada en Escobar (2017) agrega:

Las ideas relacionadas con la 'transición' representan también un marco pluriideológico que instala un espacio del debate y cuestionamiento vinculado con la gestación de una 'transformación cultural', que atañe no solo a las conceptualizaciones, posturas y definiciones aprendidas del campo del diseño, sino a la cosmogonía global que rige el ordenamiento y estructuración política, social y económica de los últimos 200 años (Di Bella, 2018, p. 176).

Para materializar la transformación que envisiona el Diseño para la Transición es necesario que el diseñador entienda su complicidad en la creación del mundo actual, y desarrolle un fuerte compromiso para intervenir en la creación del futuro; para ello es necesario que cuente con una agenda propia. Sobre esto último, Margolin (2007) reconoce que tomar una postura en un mundo cada vez más polarizado es difícil, y requiere una intensa revisión de los propios valores, metas y preocupaciones sociales; además, requiere de la capacidad para realizar alianzas con otras personas o instituciones con quienes se compartan dichas preocupaciones.

En este contexto, el diseñador se constituye en un agente de cambio que ocupa un espacio dialéctico entre el mundo que es y el mundo que puede ser (Margolin, 2007), donde el Di- 
seño para la Transición actúa como un agente integrativo entre diversos campos, permitiéndole al diseñador colaborar en equipos transdisciplinares (Irwin, Kossoff, Tonkinwise y Scupelli, 2015).

El caso del proyecto QLA es un caso complejo, ya que en él convergen actores de diferentes campos, con diferentes ideologías, quienes a través de un trabajo multidisciplinario hacen frente a los problemas complejos que aquejan a esta comunidad de mujeres artesanas. Para intervenir en un proyecto así de complejo el Diseñador de Transición requiere, además de los respectivos conocimientos profesionales, una mirada sistémica, la capacidad de generar alianzas significativas y un fuerte compromiso social y ético, es decir, adquirir y desarrollar el sentido de agencia que se mencionó anteriormente.

En cierta medida algunas de estas características representan a Cooperativa de Diseño, quiénes creen que en la Universidad predomina una mirada individualista, la del diseño de autor, y consideran necesario comprender que se puede romper aquel esquema y que es posible que el diseño sea una herramienta en un proceso más grande hacia modelos más justos y sostenibles. Sostienen que se suele educar en diseñar para las clases dominantes por lo que buscan hacerlo desde el pueblo y para el pueblo (Cambariere, 2014). Su sentido de agencia se manifiesta en cada uno de sus proyectos, la mayoría vinculados a iniciativas para reactivar la economía popular y el activismo, donde sus clientes suelen ser fábricas recuperadas, emprendimientos, grupos de artesanos, etc. Este cambio que depone un enfoque individualista y pasa a otro relacional, resulta fundamental para comprender las dinámicas complejas que debe enfrentar el Diseñador para la Transición y sobre todo para analizar los problemas intrincados que aquejan en este caso a esta comunidad qom. La intervención llevada a cabo por Cooperativa de Diseño ha logrado que el proyecto QLA impactara positivamente en las problemáticas sociales y económicas de la comunidad de mujeres qom, a través de la visibilización de su trabajo y conocimiento ancestral, de la optimización de los procesos productivos de su cestería, y la capacitación a mujeres jóvenes de la comunidad en el uso de herramientas de comunicación digital y comercialización con fines de autogestión. Sin embargo, el colectivo no consideró los complejos problemas ambientales que enfrenta la comunidad.

Por su parte, la Federación JUM, ente generador de este proyecto, también es un actor con agencia, que hace de mediador socio político y posee por lo tanto capacidad de generar alianzas significativas. Suele acompañar a la comunidad a través de acompañamiento legal, administrativo y económico y son los responsables de haber intervenido en uno de los problemas ambientales de esta comunidad. A través de su Equipo de Mapeo Comunitario acompañaron a las mujeres de la comunidad qom en el desarrollo de una propuesta de incidencia pública política para el reconocimiento de la palma como especie nativa del impenetrable chaqueño, propuesta que fue aprobada en octubre de 2017 por el Consejo Municipal de Juan José Castelli, donde se declara a la palma carandilla como especie nativa de interés dentro de la jurisdicción de la municipalidad (JUM, 20 de octubre, 2017).

Este tipo de alianzas son necesarias en la transición hacia futuros más sostenibles y son el resultado de un pensamiento contextual y relacional, que entiende que los problemas sociales, económicos y ambientales se encuentran íntimamente vinculados. 


\section{Problemáticas intrincadas que afectan a la comunidad de mujeres artesanas Qom}

Según el marco de pensamiento del Diseño para la Transición, lograr una transformación positiva a nivel cultural requiere hacer frente a problemas de alta complejidad. Estos problemas fueron definidos por Horst Rittel en la década del 70 como wicked problems o problemas perversos. Para Rittel (Irwin, 2012), los problemas perversos se clasifican según su complejidad en: problemas dóciles, problemas complejos y problemas perversos. La diferencia entre ellos es que los problemas dóciles aparentan estar bien definidos, lo que conlleva soluciones correctas o incorrectas desarrolladas a través de procesos tradicionales/lineales de diseño. En contraposición, los problemas perversos son: "problemas mal definidos, complejos, sistémicos y supuestamente sin solución. Dichos problemas están compuestos por elementos que aparentemente no guardan relación, pero sin embargo son interdependientes, pero se presentan como problemas en sí mismos, a distintos niveles o escalas (Irwin, 2012)".

En este contexto, el desafío yace en que todo problema de diseño tiene el potencial de transformarse en un problema perverso si se toman en consideración las problemáticas sociales y ambientales que lo rodean (Irwin, 2012). Bajo esta óptica, el encargo realizado por la Federación JUM a Cooperativa de Diseño se puede considerar como un problema dócil, ya que se trataba de un proyecto tradicional de diseño como el desarrollo de una identidad visual y la optimización del proceso productivo de la cestería realizada por las artesanas. Petición específica que requiere soluciones concretas.

En el caso del proyecto QLA no es posible saber a ciencia cierta si se desarrolló un mapeo de los problemas que afectan a la comunidad, sin embargo, a través de los objetivos definidos por el Fondo Ecuménico de Pequeños proyectos del Gran Chaco, se puede intentar reconstruir un bosquejo de la red de problemas complejos que rodeaban al proyecto, evidenciar sus interacciones y analizarlas desde una mirada sistémica. Entre los objetivos se encuentran problemas dóciles como: crear una marca que identifique al grupo de mujeres qom y sus productos, destacar los conocimientos y trabajos ancestrales de la cultura indígena. Problemas complejos como: fortalecer las habilidades de las jóvenes indígenas qom para el manejo de herramientas de comunicación, introducir estrategias de promoción y difusión del emprendimiento a nivel provincial y nacional. Y problemas perversos como: ejecutar estrategias de producción-comercialización de manera autónoma y sostenible.

Con la finalidad de comprender e intervenir el sistema complejo que contiene a este proyecto, a continuación se realiza una breve descripción demográfica de la comunidad qom del Chaco y de algunas de las problemáticas sociales, ambientales y económicas que la rodean (Ver Figura 2).

Los Qom -antes Toba- se encuentran asentados en su mayoría en la provincia del Chaco, específicamente en el centro de la provincia, cerca del río Bermejo, y en el oeste en la zona de El Impenetrable. En la provincia del Chaco el 3,9\% de la población se reconoce indígena lo que equivale a 41.304 personas, porcentaje que supera la media nacional en Argentina que es de 2,4\%. De ese porcentaje de la población, un 74,5\% se autorreconoce como perteneciente al pueblo Toba -qom- (INDEC, 2015). 


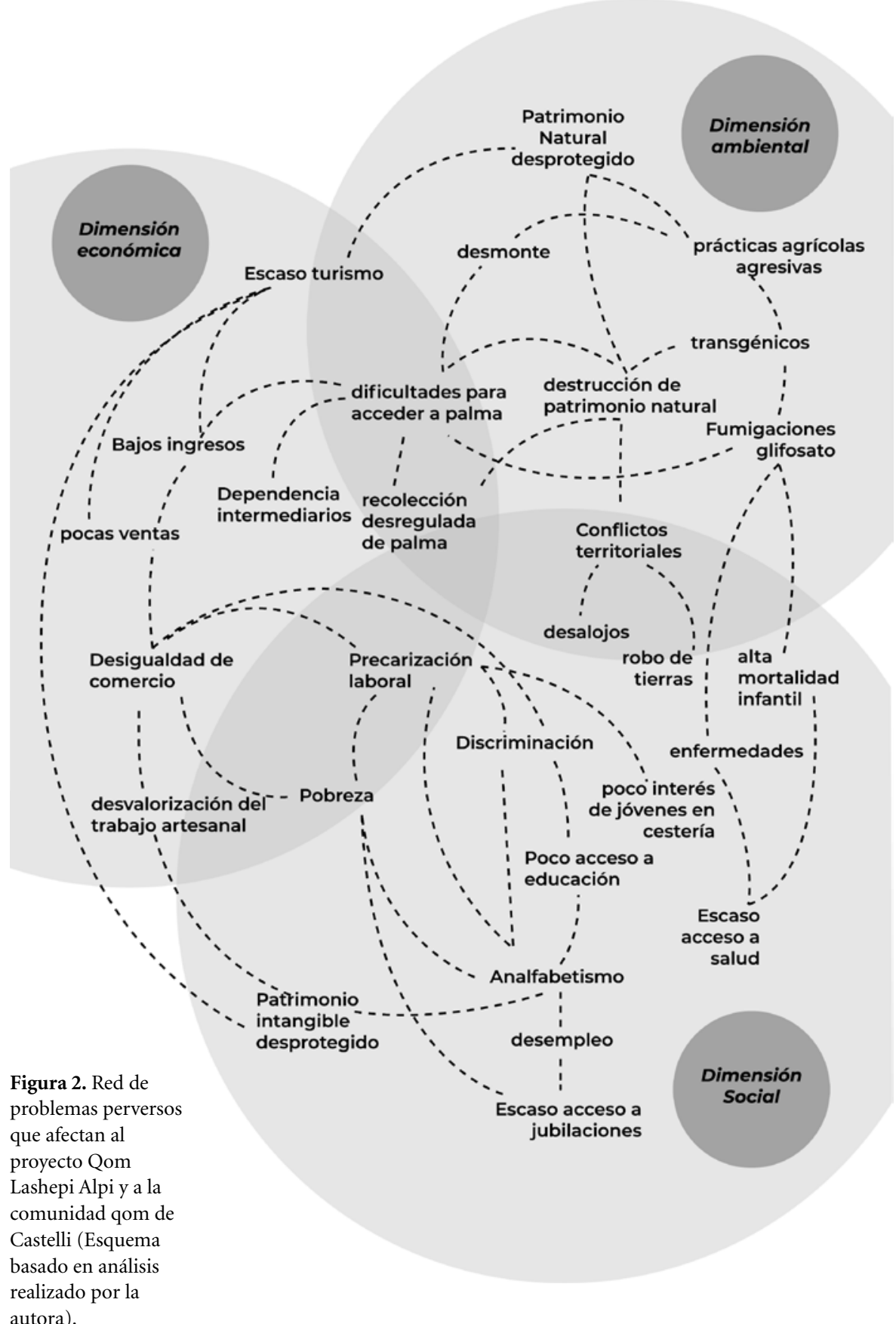


El proyecto QLA se desarrolla en la ciudad chaqueña de Juan José Castelli, que cuenta con una población de 33.651 habitantes, donde 27.201 se encuentran asentados en comunidades urbanas, 700 en zonas rurales agrupadas y 5.750 habitantes en zonas rurales dispersas (INDEC, 2012). Se estima que existen aproximadamente 600 familias qom, de las cuales 32 mujeres integran la comisión L'taaraipi y se dedican a armar canastos y adornos con hojas de palma que recolectan en la zona.

La comunidad qom de Juan José Castelli comparte muchas problemáticas de carácter social, ambiental y económico con otros pueblos originarios asentados en la provincia. Estas problemáticas no son independientes sino que se encuentran vinculadas entre sí, formando una red de problemas perversos, donde la acción sobre uno de estos problemas afecta a los otros (Irwin, 2012).

A pesar de que en 1994 la Constitución Argentina incluyó el artículo 75, inciso 17, reconociendo los derechos indígenas de los pueblos comunitarios, después de dos décadas, dichas comunidades siguen desprotegidas quedando vulnerables ante la discriminación y los abusos de poder. Particularmente se ven afectados por conflictos territoriales que siguen vigentes, y sigue sin reconocérseles la posesión de las tierras que tradicionalmente ocupan, dejándolos y exponiéndolos a robos de tierras, desalojos, apropiación y destrucción del patrimonio natural del que dependen para subsistir a nivel cultural, ambiental y económico.

Otro problema que aqueja a la comunidad indígena del Chaco es el analfabetismo, si bien la tasa de chaqueños analfabetos mayores a 10 años es ligeramente menor al promedio de provincias, existe un mayor porcentaje de analfabetismo en mujeres $(16,3 \%)$ respecto de los varones (12,4\%) (INDEC, 2015). Esta diferencia en la alfabetización de las mujeres $q o m$, tienen un alto impacto en su tasa de desocupación y en la perpetuación de la pobreza (Ponce, 2017). Según el INDEC (2015) de los 25.991 chaqueños mayores de 14 años, un $9,3 \%$ se encuentra desocupado y de ese porcentaje 632 son varones y 484 son mujeres. Esta desigualdad en el acceso a la educación marca la vida de las mujeres qom de esta comunidad, ya que en general no manejan las matemáticas, por lo tanto se les dificulta proyectar costos, realizar presupuestos y llevar las cuentas de sus ventas. Esta situación que las exponía y las expone a abusos por parte de ciertos compradores que, aprovechándose de su pobreza, imponían precios insignificantes o se llevaban la mercadería a cambio de fruta para luego revenderla. En este ultimo aspecto la Federación JUM las acompaña desde lo administrativo (Cambariere, 2014).

A este panorama se suma la discriminación y segmentación en el mercado laboral, donde se enfrentan a prácticas irregulares (Ponce, 2017). Entre las actividades laborales que realizan los hombres qom se encuentran los trabajos informales y temporarios -changas- como obreros en la construcción, o los trabajos estables en instituciones públicas. En cuanto a las mujeres, la mayoría combina el trabajo doméstico con la confección de artesanías en casa para su posterior venta. Otras mujeres qom trabajan como empleadas domésticas en las ciudades o en proyectos comunitarios (Ministerio de Educación y Deportes de la Nación, 2016). Sin embargo, quienes se encuentran asalariados reciben un ingreso precario o informal. A pesar de las condiciones laborales precarias, los jóvenes de estas comunidades prefieren emplearse en fábricas o en el sector de servicios, ya que consideran que este tipo de trabajo es menos extenuante y exigente que dominar una 
técnica artesanal, cuyo proceso de aprendizaje suele ser muy prolongado, ya que aprender los secretos del oficio no es algo que se revele a cualquiera, de hecho, este conocimiento ancestral no se revela a extraños, por lo que la falta de interés de las familias o miembros de la comunidad pone en riesgo la perpetuación de estos saberes (Unesco (s.f.).

Los problemas relacionados con el trabajo tienen consecuencias directas en la salud de los pobladores indígenas, ya que al encontrarse en situaciones de precariedad e irregularidad, se les dificulta el acceso a obras sociales y programas de jubilación. El 84\% de la población no cuenta con ningún tipo de obra social, prepaga o plan estatal y el 16\% de la población mayor a 65 años carece de jubilación (Ponce, 2017).

Por otra parte, entre las problemáticas ambientales que afectan la práctica artesanal de las mujeres qom se encuentran la deforestación, prácticas ganaderas y agrícolas de cultivo masivo e indiscriminado, como el desmonte, que perjudican directamente la recolección de la palma caranday, recurso natural del que dependen para fabricar sus tejidos y cestería. Este problema se relaciona directamente a la falta de reconocimiento por parte del Estado de su territorios ancestrales, y la falta de reconocimiento patrimonial y protección de sus saberes. Como se mencionó anteriormente, la Federación JUM acompañó en 2017 a varios grupos de mujeres artesanas qom en el proceso de creación del proyecto que, con la posterior aprobación, logró el reconocimiento de la palma caranday como especie nativa de interés y aseguró su protección municipal.

A esto se le suman otras preocupaciones ambientales como las fumigaciones agresivas en zonas aledañas del Chaco (Campo Medina, La Leonesa, Las Palmas), asociadas a empresas del sector agrícola de algodón, maíz y soja, entre otros productos transgénicos. Fumigaciones que contaminan el aire, suelo y agua del que dependen estas personas, y que además de perjudicar el crecimiento de la palma tiene graves consecuencias en la salud de estas poblaciones, donde los casos de cáncer, y malformaciones en recién nacidos se han cuadruplicado en los últimos años. Desde 2012 se dictó una medida cautelar contra ciertas empresas, pero estas las violan repetidamente (La Vaca, 2015).

Otro tema es la falta de regulación en la venta de palma seca de caranday. Esta regulación es necesaria ya que muchas mujeres artesanas no cortan la palma por si mismas por diversas razones: falta de tiempo, falta de conocimiento del territorio, falta de un medio de transporte para acceder a zonas alejadas donde se encuentra la palma, falta de dinero para el combustible de la moto, etc. Muchas mujeres están conscientes que recolectar por sí mismas la palma implica una inversión de tiempo y dinero que no pueden solventar y que dicha inversión no puede reflejarse en el precio final del producto, por lo que la artesana debe absorber ese incremento en el costo, por lo tanto, optan por comprar paquetes de palma (Qom Lashepi Alpi, 26 de noviembre, 2018). La inclusión de palma procesada en el proceso productivo debe analizarse ya que actualmente se la considera una especie nativa y se encuentra protegida, además debe asegurarse que el proceso de corte y secado no afecte el crecimiento de las palmas, ni la sostenibilidad de los sembradíos.

Otro problema relacionado con lo laboral es la falta de valorización del trabajo de las artesanas, ya que usualmente los diseñadores las consideran una proveedora de materia prima y no como alguien a la par, una diseñadora de productos finales o una colaboradora en los procesos de diseño (Diaz, 2015). El proyecto QLA realiza un aporte importante a la revalorización de la labor de la artesana qom, sin embargo queda un largo camino por re- 
correr hacia el reconocimiento y protección de los saberes ancestrales de las artesanas que representan parte del patrimonio intangible de la Argentina. Esta falta de protección por parte de los organismos estatales las deja desprotegidas ante casos de plagio y apropiación cultural por parte de marcas nacionales o extranjeras.

Finalmente el escaso turismo afecta de manera profunda la economía de estas artesanas y a la región en general, no solo porque sin visitantes no hay venta directa de artesanías, sino que además sin visitantes su realidad pasa desapercibida. Particularmente este grupo de mujeres qom no puede vivir de la venta de cestería, ya que los ingresos no son suficientes, sino que sirven de ingreso complementario (Qom Lashepi Alpi, 26 de noviembre, 2018). Esta situación las obliga a buscar clientes externos, ya sea empresas u hoteles de Buenos Aires y a depender de intermediarios (Cambariere, 2014). Esto implica un mayor esfuerzo debido a que deben gestionar también la cartera de clientes, resolver los temas de comunicación, los envíos y la cobranza.

Estos son algunos de los problemas perversos que forman parte de la compleja red que afecta a la comunidad qom. El desafío para todo Diseñador de Transición supone comprender que no se puede analizar un problema perverso, sólo se puede estudiar sus dinámicas para tratar de intervenir en ellas. Sobre esto, Irwin (2012) asegura que dichos problemas presentan una dinámica similar a la de los sistemas vivos, donde, como se constató, cada sistema está compuesto por innumerables ramificaciones de relaciones entre personas, el ambiente y las acciones de las personas -relación triádica- y por lo tanto, se necesita desarrollar soluciones con un enfoque ético y una preocupación profunda por las esferas social y ambiental.

\section{Definir cursos de acción: Intervenir la red de problemas y visualizar futuros sostenibles}

Intervenir la red de problemas complejos que contiene al proyecto para redirigir su flujo de cambio hacia futuros más positivos implica entender sus dinámicas intrincadas. Sin embargo, las dinámicas de este tipo de sistemas no pueden analizarse de forma fragmentada debido a sus principios de autoorganización, sensibilidad y emergencia, por lo que resulta casi imposible predecir su comportamiento (Morin, en Barberousse, 2008). Esto implica un riesgo para el Diseñador de Transición, ya que cada intervención en su estructura deja huellas y puede tener consecuencias inesperadas en el sistema (Irwin, 2012). Por lo tanto, decidir la implementación de acciones supone una gran responsabilidad social, ética y ambiental ya que éstas podrían afectar de forma irreversible la vida de las artesanas y de la comunidad Qom.

Para prever las consecuencias de las intervenciones realizadas en un sistema, Margolin (2007) sugiere el ejercicio de visualizar escenarios futuros predictivos -lo que podría pasar-o prescriptivos -lo que debería pasar-. La primera visualización que se realizó en base al proyecto QLA es la aplicación de la matriz Pathways in social design para proyectar y definir la escala espacio-temporal del proyecto futuro. Dicha matriz consta de dos ejes: la escala de compromiso (del diseñador o proyecto), y el rango de experiencia (Ver Figura 3). 
RANGE OF EXPERTISE brought to bear on the project

\begin{tabular}{|c|c|c|c|}
\hline $\begin{array}{r}\text { Cultural } \\
\text { (Transformation) } \\
\text { Changing the attitudes } \\
\text { and behaviors of a } \\
\text { community or } \\
\text { organization. }\end{array}$ & $\begin{array}{l}\text { - Reconocimiento del } \\
\text { Sello Buen Diseño a la } \\
\text { marca Qom Lashepi Alpi, } \\
\text { por las innovaciones de } \\
\text { producto y su respectiva } \\
\text { cobertura de prensa por } \\
\text { Lujan Cambiarere. }\end{array}$ & $\begin{array}{l}\text { Participar anualmente en } \\
\text { eventos dedicados a la } \\
\text { cultura, moda y diseño: } \\
\text { - Feria Puro Diseño } \\
\text { - BAF Week } \\
\text { - Crear con INCAA } \\
\text { documental para festivales } \\
\text { de cine locales y } \\
\text { regionales. }\end{array}$ & $\begin{array}{l}\text { Apoyo estatal para: } \\
\text { - leyes Patrimonio } \\
\text { Cultural Inmaterial (PCI) } \\
\text { - RSE con marcas de moda } \\
\text { - Incentivos estatales a } \\
\text { marcas de moda que } \\
\text { apoyen/colaboren con } \\
\text { artesanos. }\end{array}$ \\
\hline $\begin{array}{r}\text { System } \\
\text { (Innovation) } \\
\text { Altering an existing } \\
\text { system, or creating a new } \\
\text { one, to deliver a better }\end{array}$ & $\begin{array}{l}\text { - Creación y lanzamiento } \\
\text { de marca Qom Lashepi } \\
\text { Alpi, con nuevos } \\
\text { productos de cestería de } \\
\text { palma carandilla. } \\
\text { - Sistema de venta online } \\
\text { (Facebook/ whatsapp) } \\
\text { gestionado por mujeres } \\
\text { jóvenes de la comunidad. }\end{array}$ & $\begin{array}{l}\text { - Nuevos canales de venta: } \\
\text { Tienda MATRA/Malba } \\
\text { - Colaboraciones con } \\
\text { diseñadores. } \\
\text {-Integrar esfuerzos con } \\
\text { otras comunidades } \\
\text { artesanas del Chaco y } \\
\text { crear tienda online propia }\end{array}$ & $\begin{array}{l}\text { - Inclusión de las artesanas } \\
\text { qom del Chaco en el } \\
\text { registro nacional de } \\
\text { artesanos textiles de la } \\
\text { República Argentina } \\
\text { (reNATRA). Ya que su } \\
\text { técnica de trenzado de } \\
\text { fibra también es } \\
\text { considerada un tejido. }\end{array}$ \\
\hline $\begin{array}{r}\text { Stand-Alone } \\
\text { (Intervention) } \\
\text { The introduction of a } \\
\text { discrete product or } \\
\text { service }\end{array}$ & $\begin{array}{l}\text { - Optimización del proceso } \\
\text { productivo de la cestería } \\
\text { de las mujeres artesanas de } \\
\text { la comisión L'taaraipi de } \\
\text { Castelli, el Chaco. }\end{array}$ & $\begin{array}{l}\text { - Trabajo colaborativo de } \\
\text { investigación con } \\
\text { artesanas. } \\
\text { - Innovación de productos } \\
\text { de cestería para entrar a } \\
\text { nuevo mercado. }\end{array}$ & $\begin{array}{l}\text { - propuesta para el } \\
\text { reconocimiento de la } \\
\text { palma carandilla como } \\
\text { especie nativa del } \\
\text { impenetrable chaqueño, } \\
\text { protegida dentro de la } \\
\text { jurisdicción de la } \\
\text { municipalidad }\end{array}$ \\
\hline & $\begin{array}{l}\text { Individual } \\
\text { (Designer) } \\
\text { A lone person or } \\
\text { discipline. }\end{array}$ & $\begin{array}{l}\text { Interdisciplinary } \\
\text { (Team) } \\
\text { A team made up of } \\
\text { the necessary } \\
\text { expertise. }\end{array}$ & $\begin{array}{l}\text { Cross-Sector } \\
\text { (Group) } \\
\text { Requires cross } \\
\text { sector } \\
\text { participation for } \\
\text { ideation and } \\
\text { execution. }\end{array}$ \\
\hline
\end{tabular}

Figura 3. Matriz Pathways for social innovation aplicada al caso Qom Lashepi Alpi (Esquema basado en análisis realizado por la autora).

En el eje rango de experiencia individual, la primera escala del proyecto, la intervención individual, ofrece las siguientes perspectivas: Un diseñador -o un grupo de diseñadorespueden optimizar el proceso productivo de la cestería, tal como lo realizó Cooperativa de Diseño. Escalando el nivel de compromiso hasta la intervención de sistemas: Un diseñador -o grupo de diseñadores- puede desarrollar la marca Qom Lashepi Alpi para promocionar 
los productos innovadores de cestería. Y en el último escalón del nivel de compromiso, es decir, la transformación cultural: un diseñador -o grupo de diseñadores- puede participar y ganar junto con las mujeres artesanas de Castelli el reconocimiento de Sello de Buen Diseño por la innovación en productos de cestería y recibir cobertura mediática para generar conciencia.

En el eje rango de experiencia interdisciplinaria (equipos), la escala intervención individual, ofrece las siguientes perspectivas: Trabajo colaborativo de investigación con artesanas e innovación de productos de cestería, tal como lo realizó Cooperativa de Diseño. En el nivel intervención de sistemas: Un equipo interdisciplinario podría crear nuevos canales de venta como la Tienda MATRA o la tienda del Museo Malba en la Ciudad de Buenos Aires. También se podrían concretar colaboraciones con diseñadores de modas, e integrar esfuerzos con otras comunidades de artesanas del Chaco para crear una tienda online propia. Y en el último escalón del nivel de compromiso, es decir, la transformación cultural: un grupo interdisciplinario podría concretar la participación anual de las mujeres artesanas de Castelli y del Chaco en eventos dedicados a la cultura, moda y diseño como: la feria Puro Diseño en la ciudad de Buenos Aires, el BAF Week, o incluso crear en conjunto con el INCAA un documental para revalorizar sus actividades y ser mostrado local y regionalmente.

Finalmente en el eje rango de experiencia transdisciplinaria, la escala intervención indivi$d u a l$, ofrece las siguientes posibilidades: Propuesta para el reconocimiento de la palma carandilla como especie nativa del impenetrable chaqueño, tal como se realizó en conjunto con la Federación JUM. En el nivel intervención de sistemas: Un equipo transdiciplinario podría concretar la inclusión de las artesanas qom del Chaco en el registro nacional de Artesanos Textiles de la República Argentina (reNATRA). Y en el último escalón del nivel de compromiso, es decir, la transformación cultural: un grupo interdisciplinario podría concretar gestión de políticas a nivel estado para proteger el Patrimonio Natural del Impenetrable Chaqueño, y el Patrimonio Cultural Inmaterial (PCI) del que las artesanas de Castelli, del Chaco y de toda la República Argentina son guardianas. También se podrían implementar planes de responsabilidad social empresarial (RSE) a través de los Ministerios y ofrecer incentivos estatales a las marcas de moda que colaboren en la compra de tejido a las artesanas o que directamente desarrollen planes de colaboración con ellas a través de fundaciones como Gran Chaco.

La segunda fase de visualización para el proyecto QLA se basa en la herramienta Design Orienting Scenarios (DOS) propuesta por Manzini (s.f.), la misma consiste en la creación de escenarios SLOC (small, local, open, conected), en español, escenarios pequeños, locales, abiertos y conectados que desafían los sistemas globales dominantes de producción y consumo, pero incrementan la diversidad social y económica del sistema, fortaleciéndolo ante los riesgos. En este escrito se visualizará el escenario localización cosmopolita, ya que se considera que el proyecto QLA cumple con todas sus características.

La localización cosmopolita se caracteriza por la dicotomía entre el arraigo y la apertura, es decir, entre estar arraigado y pertenecer a la comunidad y el lugar, y estar abierto al flujo de ideas globales como tecnología, tendencias y dinero (Manzini, s.f.), lo que coincide con las condiciones y objetivos sobre los que fue fundando el proyecto QLA, ya que busca desarrollar una marca de cestería de producción local, pero está abierto a nuevas ideas y 
a la creación de nuevos productos, para abrirse a un nuevo mercado, sin dejar de lado su compromiso con su cultura.

Una de las características de las localizaciones cosmopolitas es fortalecer los sistemas económicos volviéndolos resilientes a nivel macro, ya que aportan a la creación de iniciativas económicas diferentes y originales, que no dependen directamente de los grandes sistemas de consumo, y por ende no se verían afectadas por fallas que poseen. En este sentido, el proyecto QLA representa una iniciativa económica diversa que genera un ingreso extra para las mujeres artesanas y representa un trabajo digno y autogestionado. De esta forma aporta a la regeneración de un tejido social debilitado por el analfabetismo, la consecuente pobreza, la discriminación y las condiciones precarias de trabajo. A esto se le puede sumar la creación de una escuela-laboratorio de tejido de palma caranday en conjunto con las Universidades Estatales, y confiar la gestión de las instalaciones a las mujeres artesanas, donde diseñadores de todo el país y la región puedan aprender los procesos productivos de la cestería, y se puedan registrar y transmitir los conocimientos para asegurar la preservación del patrimonio intangible. Esta iniciativa requeriría de colaboración y acompañamiento por parte de la Universidad para definir los métodos pedagógicos y la currícula; capacitación específica para gestionar las instalaciones, pero a la vez generaría trabajo para un sector más amplio de la población y podría ser el inicio de la creación de una serie de clusters educativos que aportarían a la descentralización de la actividad académica en el país.

Otra característica de las localidades cosmopolitas es el fortalecimiento del sentido de pertenencia, no sólo local, sino a nivel más amplio, ya que al encontrarse abiertas al flujo de influencias externas, se reconocen como un punto de conexión entre el lugar y otras culturas del mundo. Sin embargo, el Chaco, como provincia y Castelli como ciudad se encuentran aislados dentro de su propio país. Uno de los principales obstáculos económicos para la comunidad qom es la falta de turismo, ya que al no poder vender directamente sus productos dependen de intermediarios para gestionar la venta. Con el fin de activar económicamente la zona, la Fundación Gran $\mathrm{Chaco}^{3}$ ha gestionado una ruta turística, con varias subrutas, en un territorio próximo a la ruta provincial 3, desde la ruta 90 al noroeste, zona de los municipios de Presidencia Roca, Pampa del Indio, Villa Río Bermejito y El Espinillo. Se trata de La ruta de la cultura Qom y el camino de la Palma (Ver Figura 4). En 2014, mediante un taller las participantes identificaron qué servicios turísticos podrían ofrecer a los interesados en el recorrido. En general se trata de servicios donde comparten su saber y bagaje cultural con el turista, introduciéndolo a la gastronomía, a la recolección de plantas medicinales o materia prima para las artesanías, donde estos saberes compartidos son muy valorados por un turismo que se aleja del turismo de masas. Esta iniciativa "planifica acciones para generar ingresos económicos por producción y venta de artesanías" (Diario Norte, 2018) beneficiando directamente a las mujeres de Castelli, pero además contempla el fortalecimiento de la organización comunitaria y preservación de los recursos naturales. Por lo tanto, representa un gran paso hacia la resiliencia, ya que al incluir iniciativas económicas diferentes y autónomas provee de autonomía a la comunidad. Finalmente, para intervenir en los problemas perversos de esta comunidad se propone integrar al proceso de diseño lo que Meadows (en Irwin, 2012) llama leverage points, o puntos de apalancamiento. Los puntos de apalancamiento son estrategias que usan las dinámicas intrínsecas de los sistemas complejos para trabajar con ellos. 


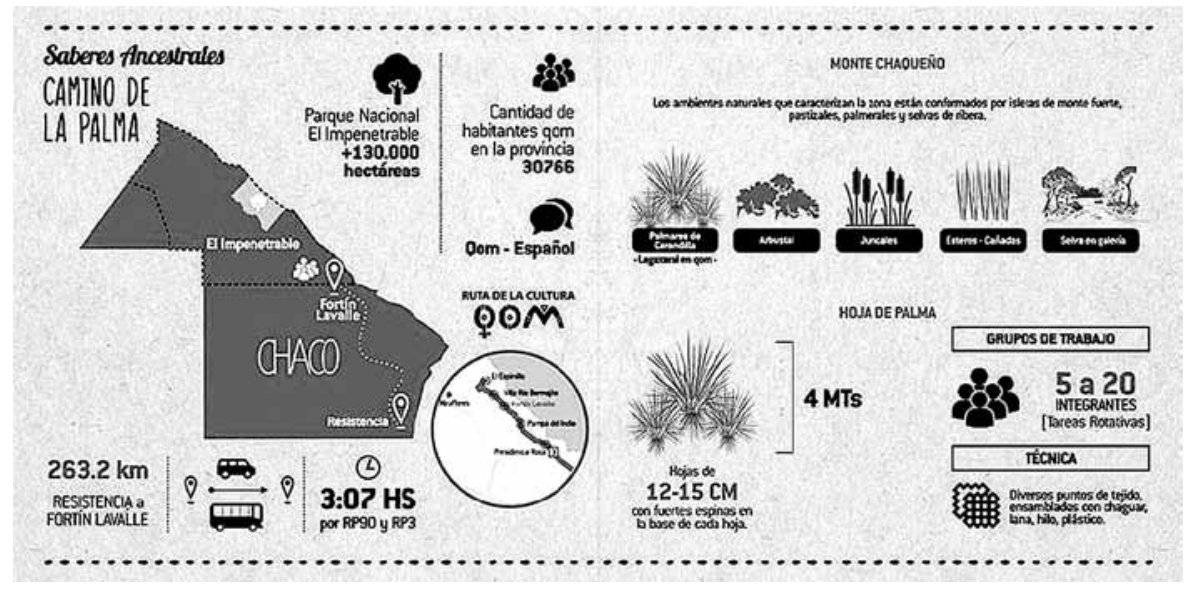

Figura 4. Localizaciones cosmopolitas. Iniciativa turística y reactivación económica: Ruta de Qom y ruta de la palma (Fuente web).

Entre los puntos de apalancamiento mencionados por Meadows está el de Information Flows o Flujos de información, enmarcado dentro del cambio en el consumo. Esta estrategia incluye enviar feedback a lugares donde no esta llegando. El proyecto QLA podría usarlo para comunicar problemas de sustentabilidad clara y de manera transparente. Otro punto de apalancamiento posible es Rules o Reglas: Incentivos, castigos, restricciones. Este indica que las reglas del sistema definen su alcance y sus límites. Para entender los problemas funcionales del sistema hay que entender las reglas que lo restringen y quién tiene poder sobre ellas. En relación a esto, es necesario entender que gran parte del problema de la comunidad tiene que ver con el abandono histórico que ha sufrido por parte de los distintos gobiernos locales y nacionales, y de la sociedad en general. Por ende, el poder lo tiene la sociedad que debe presionar a los gobiernos para que cumplan con la deuda histórica que aqueja a esta comunidad.

A continuación se muestra una lista de algunos problemas perversos que aquejan a la comunidad de mujeres artesanas y sobre los que se aplican la palancas de Flujo de información y Reglas:

- Discriminación: Enfrentar la discriminación a través de sus redes sociales, generando contenido que refleje su realidad pero que a la vez genere empatía. Para ello se necesitaría establecer estrategias de creación de contenido con Cooperativa de Diseño y capacitar a 
las jóvenes qom en la producción. A estos esfuerzos se les puede sumar la aparición en medios, ya sean medios especializados en diseño o medios más masivos como diarios, revistas y radio.

- Escaso turismo: Desarrollar campañas de comunicación para comunicar la nueva ruta de la palma, entre otros atractivos de la zona. Para esto se deberá colaborar con Cooperativa de Diseño u otros colaboradores, incluso con el Ministerio de Turismo y los gobiernos locales para gestionar un presupuesto de comunicación con el fin de posicionar a la zona como destino nacional de turismo.

- Protección del Patrimonio Natural e Intangible: Las mujeres Qom realizaron avances significativos en la protección del patrimonio natural al lograr declarar la palma carandilla como especie nativa en la zona de Castelli. Sin embargo esta acción puede escalarse a nivel cultural mediante la intervención del Estado en la formulación de leyes específicas y la declaración de zonas protegidas. Ya existen antecedentes, en 2013 la provincia de San Luis creó un Sistema de Áreas Naturales Protegidas entre las que incluye no solamente parques y reservas nacionales y provinciales, sino incluso embalses y diques, a los que considera ecosistemas artificiales importantes no solo por la regulación y provisión de agua y por constituir refugios de aves, sino también para actividades turísticas y recreativas como los deportes acuáticos y la pesca deportiva. Entre las zonas protegidas se encuentra El Parque Provincial Presidente Perón, que es el primer avance para la Reserva Provincial Palmar de Papagayos que protege porciones de Chaco Serrano y Espinal pero en particular palmares de caranday o carandilla (Subsecretaría de Planificación Territorial, 2016).

- En cuanto al reconocimiento del Patrimonio Intangible: La comisión L'taairipi debe aliarse con otros grupos de mujeres artesanas del Chaco para ser incluidas dentro del Registro Nacional de Artesanos Textiles de la República Argentina (reNATRA), gestionado por el MATRA $^{4}$ (Mercado Nacional de Artesanías Tradicionales de la Argentina) dependiente del Ministerio de Cultura de la Nación. Siendo el MATRA, el organismo encargado de generar propuestas dirigidas a consolidar el mercado interno de estos bienes, buscando proteger este tipo de producción y la calidad de vida de los artesanos (Diaz, 2015), sería conveniente considerarlo un aliado fundamental en: 1)la búsqueda de nuevos mercados para sus artesanías; 2) evaluación de su producción a través de la participación en la competencia Reconocimiento de Excelencia, donde el MATRA forma parte del comité de selección; 3 ) Incursión en nuevos mercados internos y externos; 4) puesta en valor y patrimonialización de su técnica en la gestión de leyes que protejan la palma y sus saberes ancestrales.

- Desigualdad de Comercio: Redirigir el consumo a través de la creación y comunicación de certificaciones de origen específico, certificaciones de diseño como el Sello Buen Diseño, y Sellos de Comercio Justo. Esto, sustentado en la creación de leyes y/o regulaciones de comercio justo o esquemas accesibles de certificación de comercio justo. Según Mariano Salerno, uno de los fundadores de Achalay Sustentable (La Nación, 2015) una de las certificaciones internacionales más reconocida a nivel internacional es la Organización Mundial de Comercio Justo, que también trabaja con artesanías, a su vez, asegura que en 
la Argentina existen alrededor de 20 empresas certificadas, pero paralelamente muchos productores y compañías adoptan esta filosofía sin estar bajo ningún paraguas de certificación. También asegura que se deben trabajar en esquemas de certificación o garantías que permitan a todos los productores que cumplen con los principios de comercio justo poder diferenciarse ya que no existe regulación nacional que funcione como certificación.

\section{Conclusiones}

Considerando que el presente desarrollo corresponde a un ejercicio de visualizaciones de futuros sostenibles y que se trabajó en el análisis de las dinámicas de un problema sin solución, no se puede asegurar que las propuestas realizadas sean las únicas intervenciones posibles o incluso las más acertadas para el proyecto Qom Lashepi Alpi. Sin embargo, es posible asegurar que las herramientas propuestas por el Diseño para la Transición no sólo facilitan el análisis, visualización e intervención de los problemas perversos, que todo Diseñador debe encarar en la actualidad; sino que además se convierten, por su propio mérito, en un soporte ético, que permite avizorar la escala de la responsabilidad que yace sobre el ejercicio del diseño, ya que detrás de cada decisión tomada subyacen implicaciones sociales, económicas y ambientales que afectan directamente a las comunidades de cada proyecto. Por lo tanto, la cuestión de la agencia en el ejercicio del diseño, sólo se ve superada por las implicaciones éticas y materiales de las decisiones tomadas.

Las herramientas del Diseño para la Transición resultaron de significativa utilidad para comprender que no todas las intervenciones resultarán cien por ciento sostenibles desde lo ambiental, económico o social, pero que gracias a ellas se puede intervenir en las dinámicas del sistema para lograr un futuro más positivo para la comunidad qom de Castelli, y de todo el Chaco argentino. Al realizar el escalamiento del proyecto se evidenciaron las necesidades de transformación cultural necesarias para cambiar la realidad de esta comunidad. En esta escala de compromiso es necesaria la intervención de entes gubernamentales para asegurar la protección del patrimonio natural e intangible que esta comunidad resguarda día a día. A una escala más pequeña, los procesos colaborativos resultan indispensables, tanto para acceder a nuevos canales de venta como para la inclusión de las artesanas de Castelli y el Chaco en el reNATRA. A partir de la consecución de estas fases se podrá empezar a afianzar el mercado interno de sus artesanías, y desde allí se podrán proyectar procesos de exportación o de intercambio de saberes a nivel regional e internacional.

\section{Notas}

1. La Junta Unida de Misiones (JUM) es parte del Movimiento Ecuménico formado por iglesias cristianas que, desde los valores del Evangelio, se nutre para sus acciones de servicio en el vínculo y diálogo con las comunidades indígenas reconociendo la riqueza e importancia de la diversidad cultural. Hace más de cincuenta años sus acciones defienden y promueven el desarrollo integral y armónico de los pueblos aborígenes chaqueños en el ejercicio pleno de todos sus derechos. A través de un equipo interdisciplinario se de- 
sarrollan programas que apoyan procesos autónomos que permiten a las comunidades elaborar sus propias soluciones. (JUM, s.f.).

2. La participación de Cooperativa de Diseño en esta iniciativa no es casual, ya que como su nombre lo indica, el colectivo trabaja de forma horizontal y autogestionada y su clientela está formada por fábricas recuperadas como Durax o Safra, cooperativas, pequeños emprendedores, comunidades de artesanos y otros grupos de la economía popular. El colectivo interdisciplinario está formado por 7 profesionales argentinas del diseño, ofrece servicios de diseño gráfico, industrial y audiovisual y opera dentro de la fábrica recuperada del IMPA (Industria Metalúrgica y Plástica de Argentina) ubicada en el barrio de Almagro de la ciudad de Buenos Aires (Cambariere, 2014).

3. La Fundación Gran Chaco es una organización civil sin fines de lucro que opera desde el año 2000, principalmente en las provincias de Formosa, Chaco, Salta, Jujuy, Santiago del Estero y Tucumán. Creada con el fin de promover el desarrollo duradero y el mejoramiento de la calidad de vida de las mujeres y los hombres de los diferentes pueblos del Gran Chaco Sudamericano. Promueve procesos de desarrollo local para contribuir realmente al mejoramiento de las condiciones de vida de dichas poblaciones; es por ello que una de las prioridades de Fundación Gran Chaco es no caer en metodologías asistencialistas sino fortalecer los grupos $\mathrm{u}$ organizaciones de base a fin de propender a un desarrollo endógeno y autónomo en su verdadera acepción. (Fundación Gran Chaco, s.f.)

4. La actual gestión del MATRA a través de un trabajo interministerial genera propuestas dirigidas a consolidar el mercado interno de las artesanías argentinas y su proceso de patrimonialización. Busca proteger este tipo de producción y la calidad de vida de los artesanos. El MATRA forma parte del comité de selección de piezas artesanales nacionales que compiten por el "Reconocimiento de Excelencia" para los países del Cono Sur, organizado por el World Crafts Council (WCC) con el apoyo de la UNESCO. Esta propuesta evalúa las piezas bajo rigurosos estándares de excelencia y ofrece instancias de capacitación e innovación a partir del diálogo entre artesanía y diseño. El MATRA posee desde 2015 vínculos con el Programa Iberartesanías perteneciente a la Secretaría General Iberoamericana, cuyo objetivo es contribuir a la elaboración de políticas públicas de promoción y al aumento de la competitividad de los emprendimientos del sector (Diaz, 2015, p.33-35).

\section{Referencias}

Barberousse, P. (2008). Fundamentos Teóricos Del Pensamiento Complejo De Edgar Morin. Revista Electrónica Educare. 12 (2), pp. 95-113. Heredia: Universidad Nacional.

Cambariere, L. (2014). Diseños desde el pueblo. Disponible en: https://www.pagina12.com. ar/diario/suplementos/m2/10-2796-2014-10-04.html

Daily web (2016). Una muestra de trabajo, dignidad y arraigo. Comunidad Qom en la provincia del Chaco. Disponible en: http://www.dailyweb.com.ar/noticias/val/23194/ comunidad-qom-en-la-provincia-del-chaco.html

Di Bella, D. (2018). Impacto de la experiencia Diseño en Perspectiva. Cuadernos del Centro de Estudios en Diseño y Comunicación [Ensayos] No. 80, 173-219. Buenos Aires: Facultad de Diseño y Comunicación. Universidad de Palermo. 
Diario Norte. (2018). Artesanias qom: identidad originaria. Disponible en: http://www. diarionorte.com/article/164232/artesanias-qom-identidad-originaria-

Diaz, V. (2015). Convergencias y divergencias en los modelos de negocio del sector del diseño de indumentaria argentino definidos por la incorporación de producción artesanal desde la perspectiva de la Responsabilidad Social Empresarial. Disponible en: http://bibliotecadigital.econ.uba.ar/download/tpos/1502-1036_DiazVC.pdf

Estadísticas Chaco (2010). Hogares y Viviendas CNPHyV 2010. Disponible en: http:// estadisticas.chaco.gov.ar/censos/

Fondo Ecuménico de Pequeños Proyectos Gran Chaco (2015). Proyectos apoyados en 2015. Disponible en: http://cwslac.org/comunidadesgranchaco/2015.html

Fundación Gran Chaco. (s.f.). Acerca de. Disponible en: http://www.gran-chaco.org/acerca/

Gobierno de Argentina. (s.f.). La Constitución Nacional incorpora el Artículo 75 Inc. 17. Disponible en: https://www.argentina.gob.ar/noticias/la-constitucion-nacionalincorpora-el-articulo-75-inc-17

INDEC. (2012). Censo nacional de población, hogares y viviendas 2010. Censo del Bicentenario. Resultados definitivos. Serie $B n^{\circ} 2$. 1a ed. Buenos Aires: Instituto Nacional de Estadística y Censos. Disponible en: https://www.indec.gov.ar/ftp/cuadros/poblacion/ censo2010_tomo1.pdf

INDEC. (2015). Censo Nacional de Población, Hogares y Viviendas 2010: Censo del Bicentenario. Pueblos originarios: región Nordeste argentino. 1a ed. Ciudad Autónoma de Buenos Aires: Instituto Nacional de Estadística y Censos. Disponible en: https://www.indec.gov. ar/ftp/cuadros/poblacion/pueblos_originarios_NEA.pdf

JUM. (s.f.). Quienes somos. Disponible en: http://federacionjum.org.ar/quienes-somos/

JUM. (26 de julio de 2017). Presentación de propuesta de incidencia pública. Disponible en: https://www.facebook.com/plugins/post.php?href=https\%3A\%2F\%2Fwww.facebook. com\%2FJUNTAUNIDADEMISIONES\%2Fposts\%2F830352390468212\&width=500

JUM. (20 de octubre de 2017). Declaración de especie nativa palma caranday. Disponible en: https:/www.facebook.com/plugins/post.php?href=https\%3A\%2F\%2Fwww.facebook. com\%2FJUNTAUNIDADEMISIONES\%2Fposts\%2F872664169570367\&width=500

La Vaca. (2015). La vida fumigada. Disponible en: http://www.lavaca.org/mu92/la-vidafumigada/

La Nación (2015). Comercio justo: una tendencia que crece en la Argentina de la mano del desarrollo sostenible. Disponible en: https://www.lanacion.com.ar/1821307-comerciojusto-una-tendenciaque-crece-en-la-argentina-de-la-manodel-desarrollo-sostenible

Margolini, V. (2007). Design, the future and the human spirit. Design Issues: 23 (3). Disponible en: https://www.mitpressjournals.org/doi/pdf/10.1162/desi.2007.23.3.4

Ministerio de Educación y Deportes de la Nación. (2016). Qom (tobas) y moqoit (mocovíes). Antiguas y nuevas andanzas por el Gran Chaco. 1a ed. Ciudad Autónoma de Buenos Aires: Ministerio de Educación y Deportes.

Qom Lashepi Alpi. (26 de noviembre, 2018). Grupo Qom Lashepi Alpi (ex Comisión L'taaraipi). Disponible en: https://www.facebook.com/plugins/video.php?href=https\%3A \%2F\%2Fwww.facebook.com\%2F699578573504385\%2Fvideos\%2F2207541279570089 $\% 2 \mathrm{~F} \&$ show_text $=0 \&$ width $=560$ 
Señal U Académico. (2017). Construir el diseño desde y para el pueblo. Disponible en: https://www.youtube.com/watch?v=WIBCDm6r_Fc

Subsecretaría de Planificación Territorial de la Inversión Pública. (2016). Sustentabilidad ambiental de los complejos productivos en argentina. Disponible en: https://www. mininterior.gov.ar/planificacion/pdf/planes-reg/Sustentabilidad-Ambiental-de-losComplejos-Productivos-en-Argentina-Parte-4-Region-CUYO.pdf

Tonkinwise, C. (2004). Ethics by Design, or the Ethos of Things. Design Philosophy Papers, 2(2), 129-144. Disponible en: https://doi.org/10.2752/144871304X13966215067994

Unesco. (s.f.). Técnicas artesanales tradicionales. Patrimonio Cultural Inmaterial. Disponible en: https://ich.unesco.org/es/tecnicas-artesanales-tradicionales-00057

\section{Bibliografía}

Barberousse, P. (2008). Fundamentos Teóricos Del Pensamiento Complejo De Edgar Morin. Revista Electrónica Educare. 12 (2), pp. 95-113. Heredia: Universidad Nacional.

Barbosa, O.; Mingo, G; Grippo, R.; Frutos, S.; Reziale, E.; Gamarci, A.; Corvoisier, F. (2008). Cooperativas de trabajo y pequeñas empresas solidarias en la micro-región de Paraná (Argentina). Disponible en: http://www.scielo.org.ar/scielo.php?script=sci_arttext\&pi $\mathrm{d}=$ S1851-17162008000100006

Baudrillard, J. (1978). Cultura y simulacro. Barcelona: Editorial Kairós.

Baudrillard, J. (2009). La sociedad del consumo. Sus mitos, sus estructuras. Madrid: Ed. Siglo XXI.

Bauman, Z. (2004). Modernidad Líquida. Buenos Aires: Fondo de Cultura Económica de Argentina S.A.

Becerra, P.; Cervini, A. (2005). CMD: En torno al Producto. Buenos Aires: Instituto Metropolitano de Diseño e Innovación. Díaz, E. (1999). Posmodernidad. Buenos Aires: Ed. Biblos.

Brea, G. (2014). Identidad visual para principiantes. Disponible en: http://www.guillermobrea.com/escritos/identidad-visual-para-principiantes/

Calvera, A. (Ed.) (2005). Arte ¿? Diseño. Barcelona: Gustavo Gili.

Cambariere, L. (2014). Diseños desde el pueblo. Disponible en: https://www.pagina12.com. ar/diario/suplementos/m2/10-2796-2014-10-04.html

Chaves, N. y Belluccia, R. (2003). La marca corporativa: gestión técnica del diseño de signos identificatorios institucionales. 1a ed. 4a reimp. Buenos Aires: Paidós, 2008.

Chaves, N. (2005). La imagen corporativa. Teoría y práctica de la identificación institucional. (3era ed.). Barcelona: Editorial Gustavo Gili, S.A.

Cooperativa de diseño (s.f.). Qom lashepi. Disponible en: www.cooperativadedisenio.com/ portfolio/qom/

Daily web (2016). Una muestra de trabajo, dignidad y arraigo. Comunidad Qom en la provincia del Chaco. Disponible en: http://www.dailyweb.com.ar/noticias/val/23194/ comunidad-qom-en-la-provincia-del-chaco.html

Di Bella, D. (2018). Impacto de la experiencia Diseño en Perspectiva. Cuadernos del Centro de Estudios en Diseño y Comunicación [Ensayos] No. 80, 173-219. Buenos Aires: Facultad de Diseño y Comunicación. Universidad de Palermo. 
Diario Norte. (2018). Artesanías qom: identidad originaria. Disponible en: http://www. diarionorte.com/article/164232/artesanias-qom-identidad-originaria-

Diaz, V. (2015). Convergencias y divergencias en los modelos de negocio del sector del diseño de indumentaria argentino definidos por la incorporación de producción artesanal desde la perspectiva de la Responsabilidad Social Empresarial. Disponible en: http://biblioteca digital.econ.uba.ar/download/tpos/1502-1036_DiazVC.pdf

El País. (2003). La última obra de Joan Miró. Disponible en: https://elpais.com/diario /2003/02/23/domingo/1045975961_850215.html

El País. (2008). La marca personalizada de AEG o el secreto para vivir más de 100 años. [4 párrafo]. Disponible en: https://cincodias.elpais.com/cincodias/2008/07/12/empresas /1215870000_850215.html

El País. (2015). La familia Miró anuncia su renuncia a los derechos del logotipo Turespaña. Disponible en: https://elpais.com/cultura/2015/11/27/actualidad/1448648862_176310.html

Estadísticas Chaco (2010). Hogares y Viviendas CNPHyV 2010. Disponible en: http:// estadisticas.chaco.gov.ar/censos/

Escobar, A. (2017). Diseño para las transiciones. En: Etnografías contemporáneas 3, No4 pp. 32-63. Buenos Aires: IDAES-UNSAM.

Fernandez, J. M. (2012). Capital simbólico, dominación y legitimidad. Las raíces weberianas de la sociología de Pierre Bourdieu. Madrid: Universidad Complutense de Madrid. Departamento de Sociología V.

Fondo Ecuménico de Pequeños Proyectos Gran Chaco (2015). Proyectos apoyados en 2015. Disponible en: http://cwslac.org/comunidadesgranchaco/2015.html

Fundación Gran Chaco. (s.f.). Acerca de. Disponible en: http://www.gran-chaco.org/acerca/

Gobierno de Argentina. (s.f.). La Constitución Nacional incorpora el Artículo 75 Inc. 17. Disponible en: https://www.argentina.gob.ar/noticias/la-constitucion-nacionalincorpora-el-articulo-75-inc-17

González, J. (2000). Identidad Visual Corporativa. La imagen de nuestro tiempo. Madrid: Editorial Síntesis.

González, J. (2004). La identidad visual. Concepto, evolución y nuevas perspectivas. Revista Área Abierta (8). Recuperado de: https://dialnet.unirioja.es/servlet/articulo ?codigo $=893246$

González, J. (2007). ¿Arte, estética o ideología? Disponible en: https://foroalfa.org/articulos/ arte-estetica-o-ideologia

Gráffica. (2014). ¿Quién diseñó el logo de Chupa Chups? Disponible en: https://graffica. info/logo-chupa-chups/

Grisolía, C. (2013). Problemas y retos en la construcción de los manuales de identidad visual en Latinoamérica. Buenos Aires: Universidad de Palermo. Actas de Diseño No15, p. $169-172$.

Guida, F. (2014). Generative Visual Identities. New scenarios in corporate identity. Milán: Department of Design, School of Design, Politécnico di Milano.

Irwin, T. (2012). Wicked Problems and the Relationship Triad. En Grow Small, Think Beautiful: Ideas for a Sustainable World from Schumacher College. Floris Books.

INDEC. (2012). Censo nacional de población, hogares y viviendas 2010. Censo del Bicentenario. Resultados definitivos. Serie $B n^{\circ} 2$. 1a ed. Buenos Aires: Instituto Nacional de 
Estadística y Censos. Disponible en: https://www.indec.gov.ar/ftp/cuadros/poblacion/ censo2010_tomo1.pdf

INDEC. (2015). Censo Nacional de Población, Hogares y Viviendas 2010: Censo del Bicentenario. Pueblos originarios: región Nordeste argentino. 1a ed. Ciudad Autónoma de Buenos Aires: Instituto Nacional de Estadística y Censos. Disponible en: https://www.indec.gov. ar/ftp/cuadros/poblacion/pueblos_originarios_NEA.pdf

JUM. (s.f.). Quienes somos. Disponible en: http://federacionjum.org.ar/quienes-somos/

JUM. (26 de julio de 2017). Presentación de propuesta de incidencia pública. Disponible en: https://www.facebook.com/plugins/post.php?href=https\%3A\%2F\%2Fwww.facebook. com\%2FJUNTAUNIDADEMISIONES\%2Fposts\%2F830352390468212\&width=500

JUM. (20 de octubre de 2017). Declaración de especie nativa palma caranday. Disponible en: https://www.facebook.com/plugins/post.php?href=https\%3A\%2F\%2Fwww.facebook. com\%2FJUNTAUNIDADEMISIONES\%2Fposts\%2F872664169570367\&width=500

La Nación (2015). Comercio justo: una tendencia que crece en la Argentina de la mano del desarrollo sostenible. Disponible en: https:/www.lanacion.com.ar/1821307-comerciojusto-una-tendenciaque-crece-en-la-argentina-de-la-manodel-desarrollo-sostenible

La Vaca. (2015). La vida fumigada. Disponible en: http://www.lavaca.org/mu92/la-vidafumigada/

Ledesma, M. (2010). El Diseño Gráfico, una voz pública. Buenos Aires: Wolkowicz Editores. Lorenz, M. (2016). Sistemas Visuales en Identidades dinámicas. Barcelona: Universitat de Barcelona. Departament de Disseny i Imatge. Tesis Doctoral. Disponible en: https://www. tdx.cat/handle/10803/365565? show=full

Lupton, E. (1991). The academy of deconstructed design. Disponible en: http://www.eye magazine.com/feature/article/the-academy-of-deconstructed-design

Lyotard, J. (1992). Zona Erógena. Citado en: Scatolini, J. (2011). Anales No. 41. Facultad de Cs. Jurídicas y Sociales. UNLP.

Manzini, E. (S.F.a). Design research for sustainable social innovation.

Manzini, E. (S.F.b). Resilent systems and cosmopolitan localism - the emerging scenario of the small, local, open and connected space.

Mayer, J. (2009). Prefacio. En: Baudrillard, J. (2009). La sociedad del consumo. Sus mitos, sus estructuras. Madrid: Ed. Siglo XXI.

Margolin, V. (2007). Design, the future and the human spirit. Design Issues: 23 (3). Disponible en: https://www.mitpressjournals.org/doi/pdf/10.1162/desi.2007.23.3.4

Meygide, R. (2005). Diseño y arte: Materia de Reconocimiento. En Calvera, A. (Ed.). Arte $e^{\text {? }}$ Diseño. Barcelona: Editorial Gustavo Gill.

Ministerio de Educación y Deportes de la Nación. (2016). Qom (tobas) y moqoit (mocovíes). Antiguas y nuevas andanzas por el Gran Chaco. 1a ed. Ciudad Autónoma de Buenos Aires: Ministerio de Educación y Deportes.

Morley, M. (2016). What the heck are flexible visual identities + will they replace logo centric design? En Eye On Design (AIGA Blog). Disponible en: https://eyeondesign.aiga. org/what-the-heck-are-flexible-visual-identities-will-they-replace-logo-centric-design/

Mut, M. y Breva, E. (2003). De la Identidad Corporativa a la Identidad Visual Corporativa, un Camino necesario. Universitat Jaume I. Jornades de Foment de la investigació. Recuperado de: http://repositori.uji.es/xmlui/bitstream/handle/10234/79609/forum_2003_39.pdf 
Pelta, R. (2004). Diseñar Hoy. Barcelona: Paidós Diseño.

Ponce, B. (2017). Población indígena en contexto urbano: análisis de los determinantes sociales de la salud, a partir de la información censal. Revista Geográfica Digital. IGUNNE. Facultad de Humanidades. UNNE. Año 14 (28). Disponible en: http://revistas.unne.edu. ar/index.php/geo/article/viewFile/2743/2426

Prada. (2018a). Industreality campaign. Disponible en: https://www.prada.com/us/en/ pradasphere/campaigns/2018-campaign-pre-fall-c.html

Prada. (2018b). Neon Dream campaign. Disponible en: https://www.prada.com/us/en/ pradasphere/campaigns.html

Programa de las Naciones Unidas para el desarrollo. (s.f.). Desarrollo sostenible. Disponible en: http://www.undp.org/content/undp/es/home/ourwork/sustainable-development/ overview.html

Programa de las Naciones Unidas para el desarrollo. (s.f.). Objetivos de desarrollo sostenible. Disponible en: http://www.undp.org/content/undp/es/home/sustainable-developmentgoals.html

Qom Lashepi Alpi. (26 de noviembre, 2018). Grupo Qom Lashepi Alpi (ex Comisión L'taaraipi). Disponible en: https://www.facebook.com/plugins/video.php?href =https\%3A\%2F\%2Fwww.facebook.com\%2F699578573504385\%2Fvideos\%2F220754 $1279570089 \% 2 F \&$ show_text=0\&width=560 Yotka, S. (2018) Prada Launches Instagram GIFs With Help From a Fictional It Girl. Vogue. Disponible en: https://www.vogue.com/ article/prada-instagram-gifs-lil-miquela

Raskin, P., Banuri, T., Gallopín, G., Gutman, P., Hammond, A., Kates, R., Swart, R. (2002). Great transition. The promise and lure of the times ahead. Boston: Stockholm Environment Institute.

Rettig, M. (2015). How do we work? Advancing the practice of Design for Transition. Transition Design Symposium at Carnegie Mellon University. Disponible en: https://www.academia. edu/29212770/How_Do_We_Work_Advancing_the_Practice_of_Design_for_Transition

Ritter, M. (2011). Recordando a un visionario: Peter Behrens. Recuperado de: https://foro alfa.org/articulos/recordando-a-un-visionario-peter-behrens

Roca, G. (2011). Advenimiento de la Sociedad Digital. Disponible en: http://youtu.be/ kMXZbDT5vm0S

Scatolini, J. C. (2011). El pasaje del hombre de la sociedad moderna a la posmoderna. U.N.L.P., Facultad de Cs. Jurídicas y Sociales. Anales No. 41

Señal U Académico. (2017). Construir el diseño desde y para el pueblo. Disponible en: https://www.youtube.com/watch?v=WIBCDm6r_Fc

Shakespear, L. (2011). Conferencia: ¿Qué hacen las marcas en el mundo hoy?. Uruguay: Notable Publicidad. Recuperado el 15 de septiembre de 2016. Disponible en: https:// www.youtube.com/watch?v=OrzGFFAtf4I

Subsecretaría de Planificación Territorial de la Inversión Pública. (2016). Sustentabilidad ambiental de los complejos productivos en argentina. Disponible en: https://www. mininterior.gov.ar/planificacion/pdf/planes-reg/Sustentabilidad-Ambiental-de-losComplejos-Productivos-en-Argentina-Parte-4-Region-CUYO.pdf

Tatarkiewicz, W. (1987). El arte: historia de un concepto. En Historia de seis ideas. (p. 39-78) Madrid: Tecnos. Citado en: Campi, I. (2004). Sobre la consideración artística 
del diseño: un análisis sociológico. En Calvera, A. (Ed.). Arte ¿? Diseño (p. 139 - 159). Barcelona: Gustavo Gili.

Tonkinwise, C. (2004). Ethics by Design, or the Ethos of Things. Design Philosophy Papers, 2(2), 129-144. Disponible en: https://doi.org/10.2752/144871304X13966215067994

Unesco. (s.f.). Técnicas artesanales tradicionales. Patrimonio Cultural Inmaterial. Disponible en: https://ich.unesco.org/es/tecnicas-artesanales-tradicionales-00057

\begin{abstract}
The following essay analyzes the collaborative design project Qom Lashepi Alpi, carried out by the collective Cooperativa de Diseño and the organized group of artisan women from Juan José Castelli from the province of Chaco, Argentina. It focuses on the role of the designer as an agent of social innovation for creation of more sustainable lifestyles and is based on the mapping of the network of social, economic and environmental problems that afflict this group of women of the qom community, with the aim of identify possible leveraging strategies and collaborative networks. The case is addressed from the conceptual framework of Design for Transition, the concept of resilient communities proposed by Manzini, specifically the one of cosmopolitan locations, and finally a proposal in points of intervention based on the leverage strategies developed by Donella Meadows.
\end{abstract}

Keywords: Transition Design - Collaborative design - Social innovation - Chaco - Argentina - Wicked problems - Cosmopolitan location - Leverage points - Qom community - Heritage.

Resumo: este ensaio analisa o projeto de design colaborativo Qom Lashepi Alpi, feito pelo coletivo Cooperativa de Design e o grupo organizado de mulheres artesãs de Juan José Castelli da província de Chaco, Argentina. Além, se faz foco no papel do designer como agente de inovação social para a criação de estilos de vida mais sustentáveis e está baseado no mapeamento da rede de problemas sociais, econômicos e ambientais que acometem a esta comunidade de mulheres da comunidade qom com o objetivo de identificar possíveis estratégias de alavancagem e redes de colaboração. O caso aborda-se desde o marco conceitual do Design para a Transição, o conceito das comunidades resilientes proposto por Manzini, especificamente o de localização cosmopolita, e finalmente se realiza uma proposta de palancas em pontos de intervenção baseados nas estratégias de alavancagem propostas por Donella Meadows.

Palavras chave: Design para a Transição - design colaborativo - inovação social - Chaco, Argentina - Problemas complexos - localização cosmopolita - pontos de alavancagem comunidade qom - patrimônio. 